\title{
Alliances of Change Pushing Organizational Transformation Towards Sustainability across 13 Universities
}

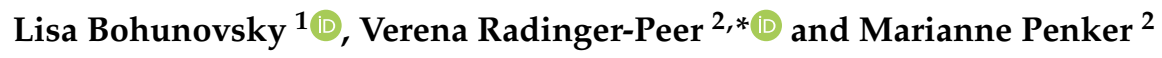 \\ 1 Center for Global Change and Sustainability, BOKU University of Natural Resources and Life Science, \\ 1180 Vienna, Austria; lisa.bohunovsky@boku.ac.at \\ 2 Institute for Sustainable Economic Development, BOKU University of Natural Resources and Life Science, \\ 1180 Vienna, Austria; marianne.penker@boku.ac.at \\ * Correspondence: verena.radinger-peer@boku.ac.at
}

Received: 25 February 2020; Accepted: 27 March 2020; Published: 3 April 2020

check for updates

\begin{abstract}
Universities are expected to play a leading role in developing and maintaining sustainability. To contribute to a systemic and dynamic understanding of organizational change that is necessary in order to play such a role, we comparatively analyzed processes of organizational changes towards sustainability across thirteen universities in Austria. This comparative analysis is based on data from guided interviews and document analysis and on validation of preliminary results via group discussion and individual comments. The results show that all universities embedded sustainability in most of their areas of activity (research, teaching, operations, organizational culture, societal engagement), but the depth of integration and the type of structural embedding varies. Especially for early changes dating back to the 1990s, academics working in the broader field of sustainability studies were those agents of change, who-without formal mandate-skillfully and proactively initiated and drove organizational transformations following an idealistic and intrinsic motivation. A timeline analysis illustrates peaks of sustainability-related changes in the years of the foundation of inter-university networks in 2011 and 2017, which acted as alliances of change. Ministry intervention in 2015 helped to bring sustainability on the agenda of those universities with less change agency. In summary, sustainability transformations across the fields of teaching, research, operations, organizational culture, and societal engagement were driven by a fruitful interplay of change agency and change alliances and to a minor degree by top-down interventions.
\end{abstract}

Keywords: universities; organizational change; higher education for sustainable development (HESD); sustainability transitions; SD; alliances

\section{Introduction}

The important role of universities as active stakeholders to support a paradigm shift towards sustainable development (SD) has been stressed both on the policy level and in the scientific discourse (e.g., [1]).

The contribution of universities to sustainable development is seen, for example, in developing strategic long-term visions and goals [2], in bridging different types of knowledge through inter- and transdisciplinary approaches [3,4], as well as assuming a boundary spanning role between science and society [5]. The role as 'change agent' [6,7] comes not without challenges. In order to fulfil this role, universities need to rethink their current organizational structures and societal purposes, leading to a structural transformation towards sustainability $[8,9]$. These processes of organizational change are expected to contribute to overarching political agendas (e.g., Education for Sustainable Development, 
Sustainable Development Goals) and involve all areas of activity: learning and teaching, operations, external societal engagement, and research.

Much research has been undertaken regarding the what of organizational transformation, including (1) the integration of sustainability in university management practices [10,11]; (2) corporate social responsibility, sustainability reporting, and accounting [12-14]; (3) teaching and education for sustainable development [15-17]; (4) generation and advancement of scientific knowledge and other forms of knowledge [18,19]; (5) boundary spanning, participation in regional sustainability initiatives, and networking [2,5,20]; and (6) applying sustainability as an overall concept for universities as in, for example, the 'sustainable university' $[4,9]$.

At the same time relatively little is known about how processes of organizational change towards SD take place [21,22]. Insights into the how of organizational change towards SD support the understanding on how to orchestrate, push, and/or support organizational change processes in universities. Furthermore, it supports the understanding on how, why, and when diverse internal and external factors influence these change processes towards SD. Understanding the how of organizational change means taking into account the deep structure and inter-personality of a university, its sub-systems, facilities, units, and departments, including their interdependencies in a systemic and dynamic understanding [23] as well as the universities' cultural orientations [24].

This makes the process of transformation particularly complex, and those who have researched or engaged in sustainability initiatives or change processes often characterize these as long, progressive, and challenging, and characterized by resistance, barriers, and contradictions $[11,25,26]$.

The subsequent aspects have been derived from the literature to enlighten the how of universities' organizational change towards SD [8,9,21,22,26-28]:

- Structural transformation and entrance of SD into universities organizational structures;

- Decision making processes, leadership strategies, and strategic planning dynamics;

- Role of internal factors (e.g., institutional culture, strategic agency, relationships and power on campus);

- Role of external factors (e.g., funding/regulative bodies, networks, other higher education institutions);

- Focus on organizational learning, to explicitly investigate the process of change.

Apart from these content wise perspectives, there is a need to investigate organizational change from a systemic and dynamic perspective [23]. Thus far, only few scholars have looked at all fields of activity from an integrative perspective and on how questions of university change processes towards SD (e.g., [27,28]) besides more theoretical work to conceptualize organizational change (e.g., [21,29]). These seminal works enfold that there is no common path for universities towards SD, but different paths driven by diverging factors. Whereby some attention has been paid to internal and external drivers of change, there is yet a lack of (a) understanding how SD entered the respective universities and what are the influencing factors behind, (b) a detailed conceptualization of what is meant by organizational change in the context of universities (an exception states [28]), and (c) a dynamic perspective on organizational change.

The present paper aims to contribute to these research gaps by investigating the how question of organizational change processes towards sustainability by scrutinizing the organizational change process of 13 Austrian public universities since the 1990s. In doing so, we explicitly focus on processes of structural transformation and embedding. The authors take a dynamic perspective to address two research questions: (a) How have the 13 universities implemented SD into the universities' organizational structures? (b) How have these changes been driven by internal and external factors? The paper is empirically based on in-depth interviews with selected stakeholders form each university as well as a complementary analysis of strategic papers, visions, and guidelines. We present long-term cross-organizational evidence from 13 universities in Austria and operationalize organizational change as the depth of integration as well as the type of structural embedding. We further enlighten the question 
on internal and external factors spurring organizational change processes. In doing so, the valuable contribution of the present paper is to (a) clearly define and operationalize organizational change in the context of universities and sustainable development, (b) take a dynamic perspective which enlightens change processes over the last decades, and (c) present data from multiple case studies which offer potential for generalization.

Section 2 presents the main elements of the analytical framework. Section 3 focuses on the methodology and the research context. Section 4 presents the results structured along the analytical framework outlined in Section 2. Section 5 discusses the results in light of the current academic debate and leads to the conclusions in Section 6.

\section{Analytical Framework}

The process of embedding sustainability into universities is discussed as a multi-faceted process of organizational learning and change, which leads to a structural transformation towards sustainability and asks for a whole-institution approach $[8,29,30]$. To ensure consistency and credibility, this structural change must involve all the areas of a university including research, teaching and learning, societal engagement, campus estates, and operations [28,31]. Our analytic framework-in line with the two research questions of the paper-provides (a) an operationalization and definition of organizational change, taking into account the depth of integration and types of change and (b) a conceptualization of the internal and external factors for spurring these organizational change processes.

\subsection{Organizational Changes-Depth of Integration and Types of Change}

When talking about organizational change, we focus on structural change, i.e., change that is embedded in universities' practices and institutions. By doing so, we set aside projects or activities that are run by an individual or a very limited number of persons and have no major organizational impact after their end. According to Ferrer-Balas et al. [28], the question of how far reaching an organizational change is, can be seen as a question

(a) of how many different persons (groups) carry or are involved in the change process and

(b) if the change is an optimization, improvement, or a real renewal of the system and

(c) if changes are only initiated or also mainstreamed within the organization.

We refer to these aspects as depth of integration and operationalize them as outlined in Table 1. The scales of the depth of organizational change thus reflect the number of persons or groups that are involved in the processes described and their distribution within the universities, but also signs of mainstreaming or system-improvement/renewal, such as e.g., university-wide integration, uptake in strategic papers, setting of new standards. Thus, changes by single actors that only affect a small group of persons are ranked lower than changes carried by a variety of actors in different entities of the university or even changes mainstreamed within universities and thus affecting all its members. Moreover, the size of the 'target groups' was taken into account, e.g., changes that affect all students were ranked higher than changes that affect only a particular group of students. 
Table 1. Operationalization and definition of organizational change (own illustration).

\begin{tabular}{|c|c|c|}
\hline $\begin{array}{l}\text { Area of } \\
\text { Activity }\end{array}$ & Depth of Integration & Type of Structural Embedding \\
\hline $\begin{array}{l}\text { Organizational } \\
\text { culture }\end{array}$ & $\begin{array}{l}0=\text { no SD relevant classes, } \\
1=\text { single SD related courses for students, } \\
2=\text { SD relevant study programs, } \\
3=\text { SD relevant programs plus obligatory SD } \\
\text { relevant classes for several/all study programs } \\
0=\text { no SD-specific research activities } \\
1=\text { single SD research activities } \\
2=\text { various, but isolated activities } \\
3=\text { broad integration and/or strategic focus on SD } \\
\text { in research activities } \\
0=\text { no/hardly any activities } \\
1=\text { single activities } \\
2=\text { activities plus some kind of certification } \\
3=\text { EMAS certification plus other activities } \\
1=\text { low ( } 1 \text { of } 4 \text { types) } \\
2=\text { middle ( } 2-3 \text { of } 4 \text { types) } \\
3=\text { high (all } 4 \text { types) } \\
\text { Types: (a) integration of SD into the scope of } \\
\text { functions of the rectorate or strong support from } \\
\text { university management, (b) integration of SD } \\
\text { into strategic papers, (c) establishment of a SD } \\
\text { board or center, (d) implementation of a broad, } \\
\text { participatory SD process } \\
* \text { Student activities as a specific form of cultural } \\
\text { embedding are analyzed separately } \\
0=\text { no focus on SD related societal engagement } \\
1=\text { SD-service-learning projects in cooperation } \\
\text { with government, public administration, schools } \\
2=\text { specific SD-related activities such as SD day, } \\
\text { SD report, SD public event series }\end{array}$ & $\begin{array}{ll}\text { 1. } & \begin{array}{l}\text { Institutional changes } \\
\text { (change of values, norms, } \\
\text { formal regulation, }\end{array} \\
\text { voluntary standards) } \\
\text { 2. } & \text { Membership } \\
\text { 3. } & \text { New organizational units } \\
\text { 4. } & \text { Working groups } \\
\text { 5. } & \text { Project/temporary events } \\
& \text { (e.g., SD days) }\end{array}$ \\
\hline
\end{tabular}

A further aspect which has to be considered under the frame of organizational change within universities is the type of structural embedding. In our work, we differentiate five sub-categories of structural embedding (adapted and extended from Pflitsch and Radinger-Peer [32]) that also relate to the question of how far reaching the change is:

1. Changes in the institutional framework, which reflect changes in rules, norms, and cognition related to SD, such as the implementation of a new formal regulation or the official announcement of new voluntary standards, which legitimize new social practices in favor of sustainability or delegitimize unsustainable behavior.

2. Memberships in a (new) organization mean the commitment and support of a network or organization and its goals. The membership in an organization does not necessarily mean structural changes within a university, but in its best sense can lead to learning processes initiated by this membership.

3. New organizations understood as establishment of new independent organizations, new study programs, or departments within a university. They are characterized by assigned responsibilities, competencies, and/or rule systems and have their own administration, technical, and/or financial resources. Thus, they are seen as relatively stable and deeply embedded in universities' structures.

4. Working groups, which are loosely coupled groups of independent actors with a common interest, usually have a non-hierarchical form and no own resources. They are thus more fluid than formal organizations, but can initiate learning processes, especially if their members come from different parts of the university who spread the ideas. 
5. Projects are institutionalized temporary events, which follow a specific purpose over a limited time, but might lead to a new structure (organization/working group). Due to the large number of SD-related activities and actors, the study does not claim to give a comprehensive overview but focusses on those activities that were reported as having led to structural changes. Especially, it does not include single classes, single research projects, or other projects that were started and ended without a structural effect.

In order to understand how these changes are initiated, the likewise influence of internal as well as external factors has to be taken into account $[27,29]$. Among the university-internal factors, leadership [27,33] and champions as agents of change $[28,34]$ are ranked first in various studies. Regarding external factors, the influence of funding and regulatory organizations but also inter-organizational networks for initiating organizational change of universities towards SD are pointed out.

\subsection{Internal Factors-Institutional Agency and Leadership}

Institutional agency defines an actor's ability to make an impact on the social order, changing the rules, relational ties, or allocation of capital within an organization. Such actors serve as agents of legitimacy who support the creation of new institutions and reform existing institutions in ways that they deem to be appropriate and aligned with their interests. So-called 'champions' and 'frontrunners' are deemed essential for any transition to sustainability [35]. They are often characterized by holding key positions at the university (e.g., rector, study program manager, head of institute) which allow them to take agency and precipitate organizational and institutional change within the university $[32,36]$ ). Commitment, leadership, and support by those 'higher-up' in universities are crucial to progress and embed sustainability [37] because it means that new structures, incentives, and funding are put in place [38]. The role of leadership is seen in guaranteeing the mainstreaming of SD-related organizational changes in contrast to mere 'cosmetic reforms' [27].

At the same time, literature on leadership argues that leadership is not just centralized but is also dispersed in the sense that leadership opportunities are available to any member of an organization, no matter what the rank [39]. Thus, leadership can come from any corner of an organization, from senior officials to students, from academia to administrative staff [22,40]. Thereby top-down and bottom-up activities interact with and reinforce each other [22]. Hoover and Harder [26] detect in their cross case synthesis that especially in sustainability initiatives 'pointing at power' is a frequent phenomenon, that means, people tend to perceive sustainability work as someone else's responsibility. “Opportunities for leadership and possibilities for change have more to do with how one sees oneself within an institution and in relation to others there than the position one holds" [25] (page 5). Therewith, the presence and the perception of power has an important role in constructing how change takes place, and who gets involved. For analyzing the university internal factors, each organizational change reported in the interviews is attributed to agency and/or leadership of one of four groups of actors in the analysis: academia, administration, management, or students, as shown in Table 1.

\subsection{External Factors-The Universities' Environment}

Modern universities may be referred to as open systems, where complex and dynamic reactions between the organization and its environment mediate through its structural operations [41]. For universities, the following elements are part of their environment: (a) government as funding/subsidizing organization, (b) other higher education institutions (and the cooperation or concurrence with them as well as a role model effect) [41,42], as well as inter-organizational networks.

Universities' activities are often driven by their sources of funding [28], therefore the government as the main funding organization but also the focus of third-party funds exerts influence on universities' organizational change processes, especially also with regard to SD.

Apart from dependence-relations, which exist between university and their funding organizations, relationships and networks are highlighted rather often in the literature as having an influence on 
organizational change processes of the university towards SD [26]. Interpersonal relationships and networks both appear to have a strong influence on the nature and development of initiatives on campus [43]. Networks fulfil different functions: they transmit data, information, and knowledge, facilitate the coordination of decisions [44], they support innovation [45], and can contribute to meta-effects through steering and self-organizing processes [46]. Networks can furthermore enable individuals without specific interpersonal connections to get involved, and bridge boundaries within and between institutions. On the other hand, they also have the potential to exclude people or groups and therewith influence who has access to power in the change process [26]. Based on their international study, Ruiz-Mallen and Heras [47] point out that university networks influence the sustainability discourse as well as practice at universities. In our analysis of external factors, we focus on incentives or pressures from government/funding organizations on the one hand and other universities and networks.

The presented analytical framework comprising organizational changes as well as internal and external factors of change built the basis for the further analysis of the empirical findings.

\section{Methods and the Research Context}

The study follows a case study approach which is recommended if the research focusses on why and how questions, if the researcher has only little control over participants' behavior, if the focused phenomenon is relevant to present time and if there is only a poorly developed data basis available [48-50]. They provide answers to how and why questions by conducting a detailed contextual analysis of underlying conditions, behavior patterns of individuals, and their relationships [51]. As single-case studies are often criticized regarding their unique conditions surrounding the specific case, multiple case studies are considered to provide more compelling and more robust evidence and more substantial analytic results, particularly if they are based on the triangulation of evidence from different sources [48] (pp. 103-119). Therefore, we opted for a multiple case and mixed methods design combining the analysis of documents, transcripts of semi-structured interviews with feedback loops of interviewees, and additional key-informants.

The case study covers 13 of 22 Austrian public universities, all of them members of the Alliance of Sustainable Universities in Austria ('Alliance'). By February 2020, 16 universities are members of the Alliance. The case study covers 13 of the 14 universities that were members in 2018 . The $14^{\text {th }}$ university did not respond to our request for interview. The Alliance is an informal network of universities that was founded in the beginning of 2012 and aims at promoting sustainability issues in Austrian universities. The member universities cover a spectrum of different types of universities. Table 2 gives an overview and lists the short names used in the following text. BOKU university hosts a coordination position for the Alliance, which is held by the first author. The main body of exchange and collaboration is the so-called expert group, which consists of persons who are nominated by the rectorates and usually have a major role in SD activities in their universities. The lead for joint activities and working groups is distributed among the members.

All case universities are subject to the Austrian university law of 2002 and are publicly funded. A slightly modified legal situation applies to DUK as a university of continuing education with an additional legal basis, the state of Lower Austria as a co-owner, and fee-based study programs. Studying at all other Austrian public universities is largely free of charge and for most study programs without restrictions to admission. The budget for universities is negotiated with the Austrian Federal Ministry of Education, Science and Research (BMWFW) every three years and is based on the so-called performance agreements. Public funding covers on average across the 22 public universities about $74 \%$ of the total budget [52], the largest part of the rest comes from external project funds. 
Table 2. Universities covered by the study, background of interview partners.

\begin{tabular}{|c|c|c|c|c|c|}
\hline ID & English Name & $\begin{array}{l}\text { Short } \\
\text { Names }\end{array}$ & Characteristics & $\begin{array}{c}\text { Alliance } \\
\text { Member } \\
\text { Since }\end{array}$ & $\begin{array}{c}\text { Interview with } \\
\text { Member of }\end{array}$ \\
\hline 1 & University of Klagenfurt & AAU & $\begin{array}{l}4 \text { faculties: technical, } \\
\text { economics, humanities, } \\
\text { interdisciplinary } \\
\text { faculty (IFF) }\end{array}$ & 2012 & academia \\
\hline 2 & $\begin{array}{c}\text { University of Natural } \\
\text { Resources and Life } \\
\text { Sciences }\end{array}$ & BOKU & life science university & 2012 & academia \\
\hline 3 & Danube University Krems & DUK & $\begin{array}{c}\text { university for continuing } \\
\text { education }\end{array}$ & 2017 & management * \\
\hline 4 & $\begin{array}{l}\text { Johannes Kepler } \\
\text { University Linz }\end{array}$ & JKU & $\begin{array}{l}4 \text { faculties: engineering } \\
\& \text { natural sci., business \& } \\
\text { social, law, medicine }\end{array}$ & 2018 & academia (2 IP) \\
\hline 5 & University of Graz & KFU & full university & 2012 & management \\
\hline 6 & $\begin{array}{l}\text { University of Music and } \\
\text { Performing Arts Graz }\end{array}$ & KUG & art university & 2012 & management \\
\hline 7 & $\begin{array}{l}\text { University of Music and } \\
\text { Performing Arts Vienna }\end{array}$ & MDW & art university & 2017 & non-scientific \\
\hline 8 & Mozarteum University & MOZ & art university & 2018 & management \\
\hline 9 & Montanuniversität Leoben & MUL & $\begin{array}{l}\text { university of mining } \\
4 \text { faculties: catholic }\end{array}$ & 2018 & management* \\
\hline 10 & University of Salzburg & PLUS & $\begin{array}{l}\text { theology, cultural/social, } \\
\text { natural sciences, law }\end{array}$ & 2012 & academia \\
\hline 11 & $\begin{array}{l}\text { Graz University of } \\
\text { Technology }\end{array}$ & TUG & technical university & 2012 & academia (2 IP) \\
\hline 12 & University of Innsbruck & UIBK & full university & 2012 & academia \\
\hline 13 & $\begin{array}{l}\text { Vienna University of } \\
\text { economics and business }\end{array}$ & WU & economics & 2012 & academia $^{2}$ \\
\hline
\end{tabular}

${ }^{1}$ Academia = scientific staff; management $=$ (vice-) rectors and staff in university management; non-scientific $=$ persons working within administration or other non-scientific position; all interview partners except those marked with * are member of the Alliance's expert group; (2 IP) = interview with 2 persons in parallel; ${ }^{2}$ the interview partner has in the meantime left WU.

Guided interviews with at least one representative of each of the above-mentioned universities were held between March and September 2018, with a duration of 50 to $90 \mathrm{~min}$ each. The interview partners were mainly members of the Alliance's expert group and were thus supposed to have a good overview over SD activities as well as the SD history of their university.

The interviews were led by the first author, partly together with the second author. The former, as coordinator of the Alliance, has good insights into the activities of each university and good relations to most of the interview partners, thus the interviews could build on a certain basis of trust and mutual knowledge and understanding. The interviews focused on the process of each university (and not the Alliance), which allowed the interviewer to remain in a neutral position, as she was not involved in these internal processes. BOKU university is an exception, as all three authors are affiliated there and are to different extents also involved in SD activities. Nevertheless, it is not possible to rule out the possibility that Alliance-related activities were mentioned to a higher extent as they represented the common point of reference for both the interviewer and the interviewees.

The interviews focused on the causes, processes, and main actors behind SD at the university and the question of how it was (historically) integrated at the university.

The interviews were recorded, transcribed, and analyzed with Atlas.ti, as shown in Figure 1) (data analysis). The aim of the qualitative content analysis [53] was to extract organizational changes along the categories operationalized in the analytic framework, as shown in Table 1, and list them according to the 
- Year of implementation;

- $\quad$ Actors driving these changes.

As the background and institutional position of the interviewees differed, a certain bias regarding the change process reported cannot be precluded. Validation of preliminary results was sought by (a) presenting and discussing them in one of the Alliance's expert group meetings; (b) sending them for comments to the interview partners; (c) sending them to the student unions of each university. Moreover, the results were triangulated with information from documents and online resources. The last step of data analysis included the attribution of each change to one of the areas of activity, the year of implementation, and the persons or groups that were involved.

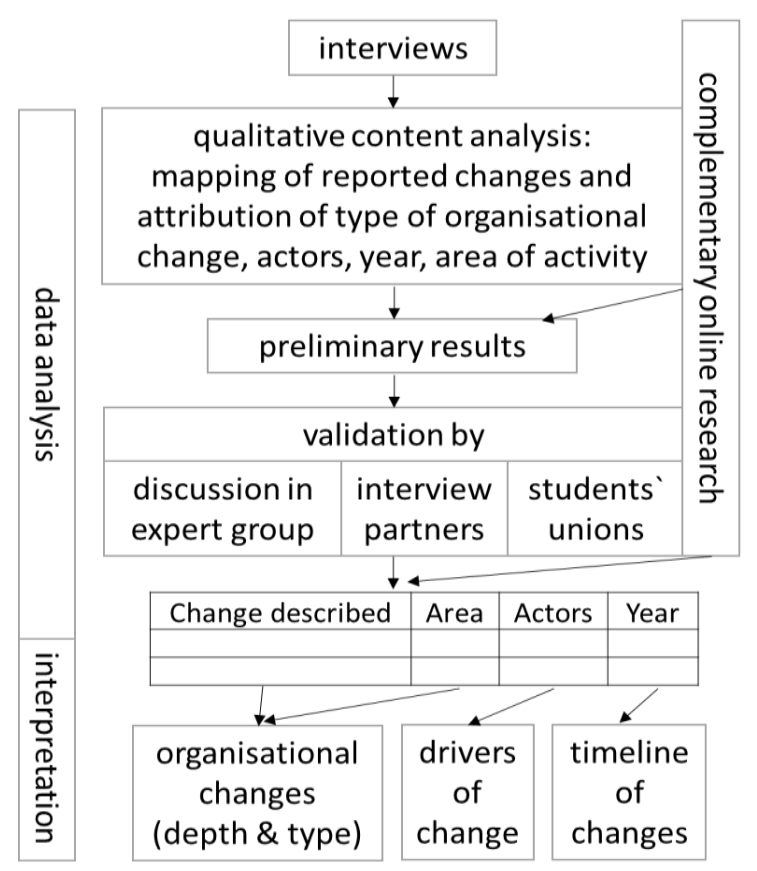

Figure 1. Process of data collection, analysis, and interpretation.

The interpretation of the empirical findings focused on comparatively analyzing the depth of integration and the type of structural embedding according to the analytic framework, as shown in Table 1. Addressing the second research question on factors of change, each organizational change reported in the interviews was attributed to agency and/or leadership of one of four university-internal groups of actors (academia, administration, management, students) and the timeline of changes is interpreted against events in the organizational field (external factors), as shown in Table 1.

\section{Results}

The first part of the results, Section 4.1, presents results on the how questions, i.e., we present evidence showing that all 13 universities embedded sustainability in research, teaching, operations, organizational culture, and/or societal engagement, and we interpret these changes in regard to their depth (Section 4.1.1), as well as in regard to types and structural effects of these changes (Section 4.1.2). The second part (Section 4.2) analyzes the second research question on internal and external factors. Moreover, the timeline of changes is interpreted along the appearance of influencing factors.

\subsection{Organizational Changes in the Case Study Universities}

The results show that universities made changes towards SD in at least three out of five areas of activities, thus SD is embedded in the whole institution. Nevertheless, changes vary in regard to the question of how deep these changes are structurally embedded. About half of the universities 
show deep or quite deep integration in all areas (AAU, BOKU, KFU, WU, PLUS, TUG, UIBK - short names according to Table 2), i.e., changes that are built on a broad basis of involved or affected persons. Others show lower levels of integration, often combined with one or two areas of activities with no integration-usually universities that only recently became members of the Alliance or also art universities. Furthermore, in regard to types of change, i.e., changes in the institutional framework, memberships, new organizations, working groups or projects, it can be observed that most of them play a role in the universities, but their relevance in regard to structural embedding varies.

\subsubsection{Depth of Integration}

The analysis addressed the question on how and how deeply the 13 universities have organizationally embedded SD into their five areas of activity, i.e., research, teaching, operations, and also activities in regard to organizational culture and societal engagement. Many case universities embed SD in most of these areas and therewith follow integral approaches. Nevertheless, these organizational changes differ in regard to the depth of structural embedding. Aggregated results according the 0-3 scale of the analytical framework, as shown in Table 1, are shown in Table 3. In the following, we argue the results by giving evidence on integration within the 13 universities.

Table 3. Embedding of sustainable development (SD) in different areas of activity of the case universities. The numbers represent the depth of integration—for details see Table 1.

\begin{tabular}{|c|c|c|c|c|c|c|}
\hline ID & University & Teaching & Research & Operations & $\begin{array}{c}\text { Organizational } \\
\text { Culture }^{1}\end{array}$ & $\begin{array}{c}\text { Societal } \\
\text { Engagement }\end{array}$ \\
\hline 1 & AAU & 2 & 3 & 3 & $2+s$ & 1 \\
\hline 2 & BOKU & $3 *$ & 3 & 3 & $3+s$ & 2 \\
\hline 3 & DUK & 2 & 2 & 0 & 2 & 1 \\
\hline 4 & JKU & 2 & 3 & 0 & 1 & 0 \\
\hline 5 & KFU & 2 & 3 & 3 & $2+s$ & 2 \\
\hline 6 & KUG & 1 & 1 & 2 & 2 & 0 \\
\hline 7 & MDW & 0 & 1 & 2 & 2 & 0 \\
\hline 8 & MOZ & 0 & 1 & 1 & 2 & 0 \\
\hline 9 & MUL & 2 & 2 & 0 & 2 & 0 \\
\hline 10 & PLUS & 1 & 2 & 3 & $2+s$ & 1 \\
\hline 11 & TUG & 1 & 2 & 2 & $2+s$ & 2 \\
\hline 12 & UIBK & 2 & 2 & 1 & $2+s$ & 1 \\
\hline 13 & WU & 3 & 2 & 3 & 3 & 2 \\
\hline
\end{tabular}

The results in the area of teaching show that only two universities (BOKU, WU) deeply integrated changes towards SD in their teaching area, whereas other universities show only limited changes in this field.

By deep integration, we mean e.g., that WU established a SD class which is obligatory for (almost) all students in their first years ('Sustainable Economics'). Thus, students are at least confronted once in their studies with SD. Or BOKU, that has SD inputs in obligatory introductory classes for three study programs and established a working group on Education for Sustainable Development (ESD) in order to promote sustainability issues in teaching. Therewith, these two universities have undergone the deepest structural change, although the depicted changes are to a large extent on a project or working group level only and therefore can be considered as improvement of the current system rather than a renewal. Although a single course during a study program cannot come up to profound education for sustainable development (ESD), it can be considered as an important step in addressing 
all students regardless of their program. Both universities also offer SD study programs (e.g., WU on Socio-Ecological Economics and Policy, BOKU on Environment and Bio-Resources Management), as well as single SD-relevant learning opportunities for students. Less deep forms of change are voluntary extension curricula on sustainability or student-organized classes for students of all study programs (e.g., AAU) or study programs for a limited number of students. The latter can be differentiated in study programs with a system approach on SD (AAU, KFU, and UIBK) and more focused study programs with an SD relation (DUK on sustainable buildings, JKU and MUL on energy). As these changes affect only a small part of the students, they are assigned a lower depth of organizational integration.

Changes in the area of research (such as the establishment of SD-relevant institutes, departments, or professorial chairs, internal sustainability research networks, research activities related to SD) exist in all research-oriented universities but they remain isolated in most universities, i.e., they are based on the commitment of few actors and have no specific support from university management. Art universities form an exception, as they participate in the UniNEtZ project (see below), but have no further research activities in regard to SD. Only four universities (BOKU, KFU, AAU, JKU) have a broader and more strategic SD focus in this area of activity. They name sustainability as one of their research priorities in their strategic papers-reflected by a higher rating in regard to the depth of integration. At BOKU, KFU, and AAU this strategic focus is moreover reflected in internal networks and cross-sectoral organizational entities covering various disciplines and approaches, which might be seen as another sign of relatively deep integration, but a fundamental change in structures and cultures still has to be proven.

One research activity that unites all except one university is the participation in the UniNEtZ project [54], a joint project of the Alliance universities, which officially started in 2019, but intensive preparatory work dates back to 2017. All case study universities except WU participate in this project. The project's aim is to elaborate an option report which supports the Austrian government to implement and reach the sustainable development goals. Although started as an informal activity of some Alliance universities, it quickly gained momentum and (a) led to the integration of 16 universities and more than 200 researchers, (b) achieved the embedding of SD into the performance agreements of all participating universities with the ministry, and (c) encouraged many universities to join the Alliance. The global initiative of the Sustainable Development Goals (SDGs) and the corresponding UniNEtZ project led to changes in the universities' environment. At the same time, it also has the potential to lead to system renewal as the project follows a fundamental shift towards "research guided to the 2030 Agenda" [55] (p. 113) and includes a great number of researchers who have the potential to spread this shift in their universities.

Changes in 'operations' refer to activities with regard to operational management, such as procurement, mobility, organization of meetings, etc. Changes in operations are not necessarily linked to teaching and research but are often seen as important in order to achieve consistency between universities' fields of action. In regard to the depth of integration, the existence of some kind of certification was considered as an important indicator. This contributes to a deeper structural effect as it is based on official standards and monitoring and thus affects the university's everyday life and therewith all university members. If taken seriously, implementing such schemes requires revision and redesign of routines, leading to substantial change towards SD. Moreover, it was found that changes in this area can either be the entrance point for a wider orientation towards sustainability (e.g., KUG and $\mathrm{MDW}$ ) or are the logical consequence of changes in other areas, like research or teaching. The latter holds true for five universities that reported no or very little focus on sustainable operations before their membership in the Alliance but are strengthening such initiatives in the meantime.

In detail, five universities (AAU, BOKU, KFU, PLUS, and WU) undergo external certification of activities in this field according to the European Eco-Management and Audit Scheme (EMAS). Although usually focusing on operational issues, e.g., AAU and KFU also report on their SD research and teaching activities within EMAS, which gives the certification an even wider scope. EMAS and its international counterpart ISO 14001 are interpreted as the deepest form of integration as they require 
reporting on and improvements in a wide range of topics covering energy, material resources, etc. Other universities follow more regional schemes like Ökoprofit (KUG) or the Viennese Eco-Business Plan (MDW), or schemes on a specific topic (e.g., TUG with ISO 50001 on energy management).

Changes within 'organizational culture' were categorized in four types, as shown in Table 1. As it is difficult to rank these different types of changes, the 4-degree scale reflects the assumption that the depth of integration depends on the amount of cultural changes. The more forms were observed in a university, the higher the depth of integration as well as the effect on university members. Again, BOKU and WU show the deepest integration of SD in their organizational culture as they implemented all types of organizational change in this area. Most other universities show at least two different types of changes and were ranked in the middle scale. Students' initiatives were analyzed separately, as they are often limited in time and it is difficult to say whether they have a long-lasting effect, although they definitely have a huge potential for inducing change. At about half of the universities, SD-related student initiatives were established.

In particular, one change that applies to almost all universities is the integration of SD into the scope of functions of the rectorate or strong support from university management (type a). This underlines the finding that support from actors of the university management is important at some point of the process (see below, Section 4.2.1). By integration of SD in strategic papers (type b), we mean e.g., the formulation of SD research priorities or stressing SD in the development plan (e.g., AAU, DUK, JKU, KFU, MDW). Type c covers the establishment of SD centers (i.e., new organizations with financial and personnel resources, with the explicit task to strengthen SD in the university, applicable for BOKU and WU) or SD boards (i.e., persons from different university entities are assigned to these boards, but no special financial and personnel resources, applicable for KFU, MOZ, PLUS, TUG). The latter is a more decentralized form of organizational change in this field. BOKU and WU also initiated a broad participatory SD process (type d), which was as well interpreted as a change of the organizational culture, as these lead to a stronger perception and acceptance of SD in the whole university. At JKU, it is mainly the research strategy with $\mathrm{SD}$ as one of three research priorities that gives a hint to a change in the organizational culture.

The area of 'societal engagement' includes changes that promote the interaction with society in regard to SD. Within the expert interviews, this area of activity was reported only fragmentary and these activities are difficult to research online, as societal engagement often is a side-product of other activities and thus difficult to differentiate from societal engagement without relation to SD. Therefore, the results in this area are least comprehensive and a simple scale to capture the depth of integration was applied.

Based on this limited information, four universities were ranked relatively high (' 2 ') as they have specific SD-related communication formats that address a larger target group-mainly annual SD days, where students, staff, and the public are invited to learn about and celebrate SD at the universities; but also SD reporting and several public SD events were reported. Another four universities were ranked with ' 1 ', as they gave accounts of projects that are conducted by single research groups with a limited range within the universities, e.g., SD service projects, i.e., projects in cooperation with the government, public administration (ministry, country administration), or schools with a strong service component for these partners. Moreover, DUK was subsumed in this category where societal engagement is a central element of their work as their students usually are in employment and directly apply their knowledge at work-but a specific SD focus is missing.

\subsubsection{Types and Structural Effects of Changes}

Five types of change were differentiated in the analysis (see conceptual framework) to better understand the how-question of organizational change towards sustainability. In the following, we present examples for each of these types and draw conclusions on their relevance in regard to structural embedding of SD. 
Changes in the institutional framework, such as the integration of sustainability in strategic papers, can be observed in all universities. They are either implemented top-down from the university management, or they are a consequence of bottom-up engagement. Especially if implemented top-down, they might, but do not necessarily lead to changes in real-life [56]. This can, for example, be observed in the case of DUK, where SD is a focus of strategic papers, but a broad integration into the university's structures and university-members' activities is still missing. Nevertheless, these changes in the institutional framework can be the starting point for further changes and are important steps towards deep and lasting institutionalization of bottom-up initiatives.

Like changes in the institutional framework, memberships in organizations do not necessarily result in real-life changes, but in some cases they did. Especially the membership in the Alliance of Sustainable Universities and the participation in its UniNEtZ project often were reported as a starting point for further organizational changes. Besides the Alliance membership, the Graz-wide network 'Sustainability $4 \mathrm{U}$ ' and the Climate Change Centre Austria (CCCA) play important roles. The latter is a research network that promotes climate research and climate impact research and fosters collaboration in and among these fields, as well as provides society and policymakers with scientifically sound information and advice on climate-relevant topics. Furthermore, the universities take part in more specific networks like the 'Responsible Science initiative' or the 'Principles for Responsible Management Education' network. As SD-relevant memberships were not systematically researched, the list is not comprehensive and only relies on these memberships reported by interviewees during the interview.

The foundation of new organizations usually is reflected in formal documents, i.e., the institutional framework. Moreover, they are mostly equipped with financial and/or personnel resources. New organizations comprise the foundation of research institutes or departments, study programs, EMAS, but also students' organizations. All universities, except two art universities, have founded some kind of new organization. TU Graz has founded a new SD organization recently. In two cases, special organizational SD entities at the university, i.e., SD competence centers, were founded to deal with SD at and beyond the university. Such competence centers play a specific role in embedding SD in universities. The two competence centers of the case study (BOKU and WU) started broad sustainability processes and took a leading and coordinating role. Therefore, they are perceived as role models by other universities.

Despite the fact, that organizations are usually equipped with financial and personnel resources and are usually reflected in the institutional framework, changes in strategic orientations of the university management can also destabilize such structures. In one case (AAU) institutes of an interdisciplinary, SD-oriented faculty were transferred to other universities following a decision from the rectorate. Due to the same reason, AAU left the Climate Change Centre Austria. Furthermore, due to changes in strategic decisions of the rectorate, the competence center for sustainability at WU shifted the focus of the center to sustainability-related research.

In contrast to new organizations, working groups and/or projects, as more short-term and informal forms of SD integration, can also be found at all universities. Interestingly, there are no SD-related working groups at those three universities (DUK, JKU, MUL) that only recently started with their SD activities and where this process was initiated rather top-down.

\subsection{Internal and External Factors of Organizational Change}

In order to answer the second research question on internal and external factors, (1) each organizational change was attributed to agency and/or leadership of one of four groups of actors in the analysis: academia, administration, management, and students, and (2) the timeline of changes is interpreted against changes in the organizational environment and the therewith presumed influences. Here, we show that academics working in the broader field of sustainability studies often were agents of change, who skillfully initiated and drove organizational changes. They mainly acted proactively without formal mandate, but out of personal interest and conviction. Furthermore, a timeline analysis (in Section 4.2.2) illustrates peaks of sustainability-related changes in the years of the foundation of 
inter-university networks, which acted as alliances of change, and ministry intervention, which helped to bring sustainability on the agenda of those universities with less change agency.

\subsubsection{Internal Factors-Agency and Leadership by Various Actor Groups}

The results show that all four actor groups play a decisive role for organizational change processes at universities, although their power and agency differ. The most prominent group in all but art universities is academic actors-numerous individual, fragmented activities from scientists in the area of environmental science and sustainability in teaching and research date back to the early 1990s and form the nucleus for later changes. The key academic institutional actors are professors, department heads, or study program managers who work in disciplines that have a proximity to SD (e.g., geography, meteorology, biology, system science) and seem to have the necessary agency and leadership abilities to initiate the alignment towards sustainability via the foundation of new institutes (e.g., AAU, JKU, UIBK), the foundation of competence centers (BOKU, WU), as well as new study programs or new specialization areas (KFU, TUG, UIBK). Based on the empirical material, the motivation of these academic actors seems to be a mixture of personal motivation and conviction, as well as their understanding of their position and power.

Nevertheless, at some point bottom-up initiatives from researchers need the support from management. At two universities (BOKU, WU), the interplay and reinforcing of academia and management was key to the initiation of comprehensive organizational change processes. Highly motivated and engaged academics, as well as a rectorate that fully supported these initiatives via new structures and additional funding, characterize these processes. Although the management's commitment and support are needed in order to successfully embed SD structures in universities, it shows that only few changes can directly be attributed to this actor group (KUG, MOZ, DUK).

The art universities show a different pattern. There, actors from management and administration have taken the lead. As there are no faculty members with a disciplinary proximity to SD at art universities, members of administration who have a strong personal connection to SD issues either take the lead and motivate the management (MDW) or they closely collaborate with-also personally motivated-members of the management.

Differences can also be detected in regard to students as a further internal actor group. At BOKU, $\mathrm{KFU}$, AAU, and UIBK, they form a kind of sparring partner for institutional change agents from academia, by mutually supporting activities and by collaborating for change. On the contrary, art universities, the DUK as a continuing education university, as well as MUL and JKU, do not show strong student engagement-which might be due to a tighter timeframe of studying and/or less affinity to the topic. The lack of student support reported for MUL and JKU might be a bias from interviewees selected from faculty and management. However, students' unions were also asked for feedback to the results and only took the opportunity in a few cases (AAU, KFU, TUG, UIBK)-which might be another indicator for less engagement.

\subsubsection{External Driving Factors and Their Influence on the Timeline of Changes}

The analysis of the coincidence of organization change and external factors shows interesting patterns when looking at the timeline of changes, as shown in Figure 2. Changes were only singular and few until the mid-2000s. Then, a steady increase of changes can be observed until 2011, when a first peak of activities can be detected for a period of 2 years (2011-2012). This peak of changes is due to activities of seven of the universities and correlates with the foundation of the Climate Change Centre Austria (CCCA) in 2011 and the foundation of the Alliance of Sustainable Universities in Austria in the beginning of 2012-going hand-in-hand with the raising importance of SD topics in the context of universities. Especially, the Alliance was often reported as a driver of change. One of the main purposes of this network is to exchange good and best practice experiences and to support SD-related changes in its member universities. 


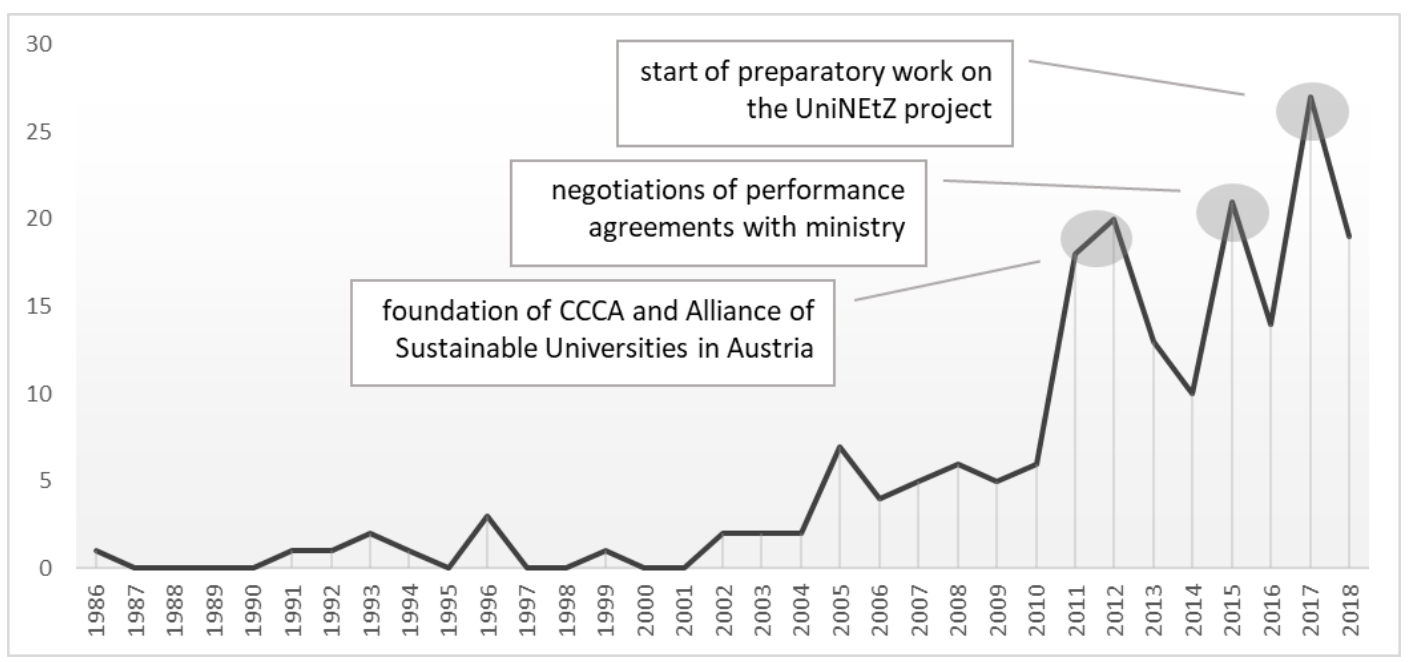

Figure 2. Number of reported changes per year excluding memberships in Alliance and Climate Change Centre Austria (CCCA), and contributions to UniNEtZ; total for all case universities.

A second peak of organizational changes towards SD in the investigated universities occurs in 2015. It correlates with the timeframe for the negotiations of the performance agreements with the ministry. The therewith template prepared by the ministry included a new aspect of the universities' contributions towards SD. Although the ministry cannot directly impose SD on a university, it can stress the topic's importance by including it in the reporting forms that universities use. This happened in 2015, and although not explicitly mentioned in the interviews, the increasing number of changes from 2015 on might be attributed to this.

A further external driver for changes was the Agenda 2030, published and agreed on by all UN member states in 2015. By signing the Agenda, Austria obliged itself to accomplish the Sustainable Development Goals and called on its institutions to support this endeavor. The call was taken up by scientists from the Alliance. They started the UniNEtZ project, which again boosted many SD-relevant changes at the universities and led to the accession of four further universities to the Alliance.

\section{Discussion}

Based on the detected research gaps, the present paper aims to investigate how universities implemented organizational change towards sustainability and how these organizational changes have been driven by external and internal factors. The scientific insights gained are compared with the scientific state-of-the-art in this section.

The results show that all 13 analyzed universities have implemented SD in most or even all areas of activities, i.e., research, teaching, operations, organizational culture, and societal engagement, and thus come up to the call for an integrative approach (e.g., $[21,27,28,31])$, although the depth of integration varies. While Lozano [57] stated in 2015 that "in general, the implementation of SD in HEIs [Higher Education Institutions] has been compartmentalized and not holistically integrated throughout the institutions" (p. 14), most of the analyzed universities follow an integrative approach. Some of the reported changes only affect small aspects of a university, but the fact that the universities show efforts in most areas of activity indicate that the ideas are integrated holistically. Moreover, the depth of integration was taken into account-operationalized by the number of persons involved, signs of mainstreaming, or system renewal—building on Ferrer-Balas [28]. Some universities show deep changes in all areas of activity, such as AAU, BOKU, KFU, UIBK, and WU. Those universities that show lower levels of intensity and a stronger focus on single areas are, on the one hand, art universities that lack research with a proximity to the topic, or on the other hand, universities that have started the process recently and rather top-down from the university management. Nevertheless, all universities show structural embedding in at least three of the five analyzed areas of activity. 
The driving forces behind these changes can be observed in many internal and external factors. Our study reveals academic staff as a major driver for change in about half of the cases-single actors who initiated changes based on their personal motivation and engagement. This adds an important aspect to Barth [27], who differentiated between student-, operations-, and unique selling-point-driven implementation processes of SD and saw the role of academic staff rather as transmitters than as factors of change. Through the intrinsic personal motivation of single researchers, in combination with their position and decision-making power, processes of structural embedding were initiated-not only in the area of research. Thus, they acted as institutional change agents [36] who make the university management support their endeavors and not vice versa [26,32]. In many cases, a certain awareness for environmental and sustainability issues was already established, though fragmented, which formed the seedbed for organizational change (foundation of new institutes, centers, new university courses or study programs).

Nevertheless, it needs a good interplay between bottom-up engagement and the university management-at least at some point of the process. Ideally, the management's endeavors are backed and supported by incentives from funding organizations. On the downside, missing or withdrawn support can end changes quickly. In this sense, our results support the findings of Heck [40] and Lozano [11] that a strong interplay of bottom-up engagement with top-down support leads to a broad embedding in various areas of activity of the university. Within all universities the university management and rectorate played a decisive role to bring SD on the agenda at some point of the process. We interpret these developments in the Austrian case as consequences of the organizations' environmental influence-in 2015 the ministry included SD into the template of the performance agreement and from 2017 reinforced its intention to extend universities' participation in the Alliance and the UniNEtZ project. This gentle pressure changed the regulative framework and induced organizational change processes in the mentioned cases. The support of the rectorate/leadership is essential to ensure continued existence of new organizational structures. Several times new developments (towards or away from) SD go hand in hand with changes of leadership on the top-management level. On the contrary, the loss of leadership support or changing strategic orientation in the university management also led to a weakening of established structures (see the example of the AAU SD faculty).

Students have a very specific role in SD processes [22,58]. First, they as a main 'target/stakeholder group' of universities have the legitimacy to call for changes towards sustainability. It is their generation that will be affected most by an un-sustainable development, which adds another form of legitimacy and an intrinsic motivation to call for changes. Nevertheless, not all students seem to have a personal motivation and interest in the topic, which seems also to depend on the study program in which they are enrolled. Second, they are very fluent groups as they usually only stay for a couple of years, which makes it difficult to provide continuity to their actions. Third, they are "easy to motivate, but difficult to organize" [58] (page 112), as their calendars and time management differs from university staff. These differences can also be seen in the results-universities with study programs related to SD tend to have more active students. In the case of PLUS, it was even them who initiated changes by proposing them to the rectorate- but then the group of students dispersed quickly.

Usually, universities started their process from one area of activity-with a further diffusion to other areas. Although it is difficult to attribute these broadening patterns simply to the membership in the Alliance, the exchange between actors from different universities, continuous confrontation with new ideas, and a certain normative pressure from within the network seem to have supported these developments. Those universities that started from engagement in operations, show similar patterns as observed by Barth [27], by focusing on changing daily routines. The initial factor varies, from single actors with or without a leading position to isomorphism [59], trying to copy a path that was taken by similar universities before. The latter holds true for art universities. Nevertheless, these universities broadened their activities incrementally (broader embedding of SD in strategic papers or in research activities, etc.). Universities starting from research activities also show a pattern towards broadening, 
as they usually started with single actors, lectures, research topics, and later started with activities in operations, teaching, etc.

Apart from institutional agents and leadership, we further detect the following influencing factors in the universities' environment, which initiated structural changes towards SD: networks and alliances, and the ministry (regulative environment). The reported and observed effects (increase in changes towards SD) support the assumption that the Alliance and similar networks strengthen institutional change agents by making SD a relevant topic at the university and by enabling the learning from others of how to initiate, accelerate, and mainstream change. These findings are in line with Ruiz-Mallen and Heras [47] who emphasize that these type of (university) networks influence the sustainability discourse as well as practice at universities. Accordingly, our results reveal a correlation between the foundation of the Alliance, the CCCA, and the start of the UniNEtZ project and the number of SD-related changes at the member universities (see also Section 4.2.2). The functions of networks in transmitting information, knowledge, support of innovation, and steering processes described in the literature [44-46] is in accordance with the observed reasons for universities to join the Alliance-interest to support this topic combined with a search for support and guidance. For some universities, the membership in the Alliance stood in the beginning of their endeavors (like the participation in the UniNEtZ project), for other universities it was a logical consequence of already ongoing SD activities—but still seeking to increase effectiveness through networking.

The UniNEtZ project functioned as another re-enforcing mechanism. Initiated by the Alliance, it soon gained strong support from the ministry, which then called on other universities to join the project before and during negotiations of the performance agreements. The participation in the project made many universities also join the Alliance.

While the network of the Alliance exerts mimetic and normative influence [59] on universities, the Austrian Federal Ministry of Education, Science and Research exerts coercive power via the performance agreements, which are the basis for the negotiations between the university and the ministry. Other influencing factors with a normative effect are international/global developments such as Agenda 2030. Via this international discourse, the topic of SD got extra attention and momentum.

Before summarizing the general implications of our research, the following limitations have to be taken into account. The study focuses on public universities in Austria, as the Alliance network until now is limited to this type of higher education institution. Furthermore, the background and institutional position of the interviewees differed, therewith a certain bias regarding the change process reported cannot be precluded. Although our investigations have a dynamic perspective, even more in-depth interviews with actors from various backgrounds, inside and outside the university would be necessary to explore the processes of change in detail at each university.

Nevertheless, the following findings can be generalized to other (semi-)autonomous public universities. First, organizational change processes towards SD in universities are complex and characterized by numerous parallel developments, a diverse range of actors involved, and are influenced differently by internal and external factors. It became also evident that various development paths can be taken leading to organizational transformations towards SD. Second, the important role of individual (often, but not only academic) actors, which due to their motivation and position, enact change towards SD has to be pointed out. If single actors or single actor groups manage to act skillfully within the opportunities given by networks, university management, and, ideally, funding organizations, they can exert a huge changing power. Third, the university management and rectorate have an important enabling role, providing windows of opportunity, funding, or other types of support (e.g., foundation of new organizational units, personnel, or financial resources, incorporation into university strategies). The universities with the most comprehensive and advanced organizational transformations towards SD are those where a fruitful interplay between the rectorate and the individual (academic) actor has taken place. Fourth, the role of inter-university networks is crucial to start the dialogue on certain (SD) topics, to provide room for discussion, as well as joint-action. These SD-focused networks initiate mimetic and normative influence and state important 
platforms for change agents. We hope that our findings inspire more scientific investigations on whole-institution organizational change processes towards SD, especially focusing on other national and international settings. While we operationalized organizational change as depth of integration and type of structural embedding, further research could pay more attention to how these changes are legitimized and institutionalized. Moreover, experiences from other countries and also diverse higher education institutions could further enrich the current academic discourse.

\section{Conclusions}

The comparative analysis illustrates thirteen Austrian universities' organizational change processes towards sustainability in the areas of teaching, research, operations, organizational culture, and societal engagement. Academics working in the broader field of sustainable studies were change agents, who skillfully and proactively initiated and drove organizational change. A timeline analysis illustrates peaks of sustainability-related changes related to the years of the foundation of three inter-university networks. These alliances of change, in a fruitful interplay with academic change agents, have further pushed organizational change towards sustainability. Management and rectorates, as well as ministry, played an important role in bringing sustainability on the agenda of those universities following later. In a nutshell, the thirteen universities have implemented organizational change towards sustainability by an interplay of intra-university change agency and inter-university change alliances, complemented by more coercive management and ministry interventions pushing sustainability transformations in the group of late followers.

Author Contributions: Conceptualization, V.R.-P., L.B., M.P.; methodology, L.B., V.R.-P.; investigation, L.B., V.R.-P.; data curation, L.B.; writing—original draft preparation, V.R.-P., L.B.; writing—review and editing, M.P., V.R.-P. All authors have read and agreed to the published version of the manuscript.

Funding: This research was partially funded by the Austrian Science Fund, grant number T761-G27.

Acknowledgments: Open Access Funding by the Austrian Science Fund (FWF). The authors grant special thanks to the three anonymous reviewers for their valuable feedback and input, which helped us to reconsider and elaborate further on main parts of the paper.

Conflicts of Interest: The authors declare no conflict of interest.

\section{References}

1. Adomssent, M.; Michelsen, G. German Academia heading for sustainability? Reflections on policy and practice in teaching, research and institutional innovations. Environ. Educ. Res. 2006, 12, 85-99. [CrossRef]

2. Zilahy, G.; Huisingh, D. Roles of academia in Regional Sustainability Initiatives. J. Clean. Prod. 2009, 17, 1053-1056. [CrossRef]

3. Caniëls, M.C.J.; van den Bosch, H. The role of Higher Education Institutions in building regional innovation systems. Pap. Reg. Sci. 2011, 90, 271-286. [CrossRef]

4. Adomßent, M.; Godemann, J.; Michelsen, G. Transferability of Approaches to Sustainable Development at Universities as a Challenge. Int. J. Sustain. High. Educ. 2007, 8, 385-402. [CrossRef]

5. Pflitsch, G.; Radinger-Peer, V. Developing Boundary-Spanning Capacity for Regional Sustainability Transitions-A Comparative Case Study of the Universities of Augsburg (Germany) and Linz (Austria). Sustainability 2018, 10, 918. [CrossRef]

6. Peer, V.; Stoeglehner, G. Universities as change agents for sustainability-Framing the role of knowledge transfer and generation in regional development processes. J. Clean. Prod. 2013, 44, 85-95. [CrossRef]

7. Stephens, J.C.; Hernandez, M.E.; Román, M.; Graham, A.C.; Scholz, R.W. Higher education as a change agent for sustainability in different cultures and contexts. Int. J. Sustain. High. Educ. 2008, 9, 317-338. [CrossRef]

8. Tilbury, D. Education for Sustainable Development: An Expert Review of Processes and Learning; Unesco: Paris, France, 2011.

9. Velazquez, L.; Munguia, N.; Platt, A.; Taddei, J. Sustainable university: What can be the matter? J. Clean. Prod. 2006, 14, 810-819. [CrossRef] 
10. Arbo, P.; Benneworth, P. Understanding the Regional Contribution of Higher Education Institutions: A Literature Review. In OECD Education Working Papers; OECD Publishing: Paris, France, 2007; Volume 9.

11. Lozano, R. Incorporation and institutionalization of SD into universities: Breaking through barriers to change. J. Clean. Prod. 2006, 14, 787-796. [CrossRef]

12. Zadek, S.; Radovich, S. Governing Collaborative Governance. Enhancing Development Outcomes by Improving Partnership Governance and Accountability. In Working Paper 23; John, F., Kennedy School of Government, Harvard Kennedy School, Eds.; AccountAbility and the Corporate Social Responsibility Initiative: Cambridge, MA, USA, 2006.

13. Lozano, R. The state of sustainability reporting in universities. Int. J. Sustain. High. Educ. 2011, 12, 67-78. [CrossRef]

14. Aras, G.; Crowther, D. Governance and sustainability: An investigation into the relationship between corporate governance and corporate sustainability. Manag. Decis. 2008, 46, 433-448. [CrossRef]

15. Cortese, A.D. The critical role of higher education in creating a sustainable future. Plan. High. Educ. 2003, 31, $15-22$.

16. Dlouhá, J.; Huisingh, D.; Barton, A. Learning networks in higher education: Universities in search of making effective regional impacts. J. Clean. Prod. 2013, 49, 5-10. [CrossRef]

17. Lee, Y.S.; Schottenfeld, M.A. Internationalising Experiential Learning for Sustainable Development Education. J. Educ. Sustain. Dev. 2012, 6, 341-354. [CrossRef]

18. Waas, T.; Verbruggen, A.; Wright, T. University research for sustainable development: Definition and characteristics explored. J. Clean. Prod. 2010, 18, 629-636. [CrossRef]

19. Filho, W.L. About the Role of Universities and Their Contribution to Sustainable Development. High. Educ. Policy 2011, 24, 427-438. [CrossRef]

20. Dlouhá, J.; Barton, A.; Huisingh, D.; Adomssent, M. Learning for sustainable development in regional networks. J. Clean. Prod. 2013, 49, 1-4. [CrossRef]

21. Baker-Shelley, A.; van Zeijl-Rozema, A.; Martens, P. A conceptual synthesis of organisational transformation: How to diagnose, and navigate, pathways for sustainability at universities? J. Clean. Prod. 2017, 145, 262-276. [CrossRef]

22. Stephens, J.C.; Graham, A.C. Toward an empirical research agenda for sustainability in higher education: Exploring the transition management framework. J. Clean. Prod. 2010, 18, 611-618. [CrossRef]

23. Yarime, M.; Trencher, G.; Mino, T.; Scholz, R.W.; Olsson, L.; Ness, B.; Frantzeskaki, N.; Rotmans, J. Establishing sustainability science in higher education institutions: Towards an integration of academic development, institutionalization, and stakeholder collaborations. Sustain. Sci. 2012, 7, 101-113. [CrossRef]

24. Niedlich, S.; Kummer, B.; Bauer, M.; Rieckmann, M.; Bormann, I. Cultures of sustainability governance in higher education institutions: A multi-case study of dimensions and implications. High. Educ. Q. 2019, 1-18. [CrossRef]

25. Barlett, P.F.; Chase, G.W. Sustainability on Campus: Stories and Strategies for Change; MIT Press: Cambridge, MA, USA, 2004.

26. Hoover, E.; Harder, M.K. What lies beneath the surface? The hidden complexities of organizational change for sustainability in higher education. J. Clean. Prod. 2015, 106, 175-188. [CrossRef]

27. Barth, M. Many roads lead to sustainability: A process-oriented analysis of change in higher education. Int. J. Sustain. High. Educ. 2013, 14, 160-175. [CrossRef]

28. Ferrer-Balas, D.; Adachi, J.; Banas, S.; Davidson, C.I.; Hoshikoshi, A.; Mishra, A.; Motodoa, Y.; Onga, M.; Ostwald, M. An international comparative analysis of sustainability transformation across seven universities. Int. J. Sustain. High. Educ. 2008, 9, 295-316. [CrossRef]

29. Cebrián, G.; Grace, M.; Humphris, D. Organisational learning towards sustainability in higher education. Sustain. Account. Manag. Policy J. 2013, 4, 285-306. [CrossRef]

30. Sterling, S. Higher education, sustainability, and the role of systemic learning. In Higher Education and the Challenge of Sustainability; Corcoran, P.B., Wals, A.E., Eds.; Kluwer Academic Publishers: Dordrecht, The Netherlands, 2004; pp. 49-70.

31. Ferrer-Balas, D.; Lozano, R.; Huisingh, D.; Buckland, H.; Ysern, P.; Zilahy, G. Going beyond the rhetoric: System-wide changes in universities for sustainable societies. J. Clean. Prod. 2010, 18, 607-610. [CrossRef]

32. Radinger-Peer, V.; Pflitsch, G. The role of higher education institutions in regional transition paths towards sustainability. Rev. Reg. Res. 2017, 37, 161-187. [CrossRef] 
33. Fullan, M.; Scott, G. Turnaround Leadership for Higher Education; Jossey-Bass: San Francisco, CA, USA, 2009.

34. Ryan, A. Education for Sustainable Development and Holistic Curriculum Change. A Review and Guide; The Higher Education Academy: York, UK, 2011.

35. Loorbach, D.; Rotmans, J. The practice of transition management: Examples and lessons from four distinct cases. Futures 2010, 42, 237-246. [CrossRef]

36. Haunschild, P.; Chandler, D. Institutional-level learning: Learning as a source of institutional change. In The Sage Handbook of Organizational Institutionalism; SAGE Publications: Thousand Oaks, CA, USA, 2008; pp. 624-649.

37. Lozano-García, F.J.; Huisingh, D.; Delgado-Fabián, M. An interconnected approach to incorporate sustainable development at Tecnológico de Monterrey. Int. J. Sustain. High. Educ. 2009, 10, 318-333. [CrossRef]

38. Holmberg, J.; Svanström, M.; Lundqvist, U.; Svanström, M.; Arehag, M. The university and transformation towards sustainability. Int. J. Sustain. High. Educ. 2012, 13, 219-231. [CrossRef]

39. Ancona, D. Leadership in an Age of Uncertainty. MIT Cent. Bus. Res. Brief 2005, 6, 1-4.

40. Heck, R.H.; Hallinger, P. The Study of Educational Leadership and Management. Where Does the Field Stand Today? Educ. Manag. Adm. Leadersh. 2005, 33, 229-244. [CrossRef]

41. Scott, W.R. Instituitions and Organizations; Sage: Thousande Oakes, CA, USA, 2001.

42. Pinheiro, R. In the Region, for the Region? A Comparative Study of the Institutionalisation of the Regional Mission of Universities; University of Oslo: Oslo, Norway, 2011.

43. Bardati, D.R. The integrative role of the campus environmental audit: Experiences at Bishop's University, Canada. Int. J. Sustain. High. Educ. 2006, 7, 57-68. [CrossRef]

44. Lambooy, J. The transmission of knowledge, emerging networks, and the role of universities: An evolutionary approach. Eur. Plan. Stud. 2004, 12, 643-657. [CrossRef]

45. Mader, C. How to assess transformative performance towards sustainable development in higher education institutions. J. Educ. Sustain. Dev. 2012, 6, 79-89. [CrossRef]

46. Mayntz, R.; Scharpf, F.W. Der Ansatz des aktuerzentrierten Institutionalismus. In Gesellschaftliche Selbstregelung und Steuerung; Mayntz, R., Scharpf, F.W., Eds.; Campus: Frankfurt am Main, Germany, 1995.

47. Ruiz-Mallén, I.; Heras, M. What Sustainability? Higher Education Institutions' Pathways to Reach the Agenda 2030 Goals. Sustainability 2020, 12, 1290. [CrossRef]

48. Yin, R.K. Case Study Research Design and Methods, 5th ed.; Sage Publications: Thousand Oaks, CA, USA, 2014.

49. Corcoran, P.B.; Walker, K.E.; Wals, A.E.J. Case studies, make-your-case studies, and case stories: A critique of case-study methodology in sustainability in higher education. Environ. Educ. Res. 2004, 10, 7-21. [CrossRef]

50. Kyburz-Graber, R. Case study research on higher education for sustainable development. Epistemological foundation and quality challenges. In Routledge Handbook of Higher Education for Sustainable Development; Barth, M., Michelsen, G., Rieckmann, M., Thomas, I., Eds.; Routledge: London, UK, 2016; pp. 126-141.

51. Baxter, P.; Jack, S. Qualitative Case Study Methodology: Study Design and Implementation for Novice Researchers. Qual. Rep. 2008, 13, 544-559.

52. Bundesministerium für Bildung, Wissenschaft und Forschung. Universitätsbericht 2017; Bundesministerium für Bildung, Wissenschaft und Forschung: Wien, Austria, 2018.

53. Mayring, P. Qualitative Inhaltsanalyse. In Grundlagen und Techniken, 12th ed.; Beltz: Weinheim, Germany; Basel, Switzerland, 2010.

54. Stötter, J.; Kromp-Kolb, H.; Körfgen, A.; Allerberger, F.; Lindenthal, T.; Glatz, I.; Lang, R.; Fehr, F.; Bohunovsky, L. Österreichische Universitäten übernehmen Verantwortung: Das Projekt Universitäten und Nachhaltige EntwicklungsZiele (UniNEtZ). GAIA Ecol. Perspect. Sci. Soc. 2019, 28, 163-165. [CrossRef]

55. Independent Group of Scientists appointed by the Secretary-General. Global Sustainable Development Report 2019: The Future is Now-Science for Achieving Sustainable Development; United Nations: New York, NY, USA, 2019.

56. Lozano, R.; Lukman, R.; Lozano, F.J.; Huisingh, D.; Lambrechts, W. Declarations for sustainability in higher education: Becoming better leaders, through addressing the university system. J. Clean. Prod. 2013, 48, 10-19. [CrossRef]

57. Lozano, R.; Ceulemans, K.; Alonso-Almeida, M.; Huisingh, D.; Lozano, F.J.; Waas, T.; Lambrechts, W.; Lukman, R.; Hugé, J. A review of commitment and implementation of sustainable development in higher education: Results from a worldwide survey. J. Clean. Prod. 2015, 108, 1-18. [CrossRef] 
58. Lukman, R.; Glavič, P. What are the key elements of a sustainable university? Clean Technol. Environ. Policy 2007, 9, 103-114. [CrossRef]

59. DiMaggio, P.J.; Powell, W.W. The Iron Cage Revisited: Institutional Isomorphism and Collective Rationality in Organizational Fields. Am. Sociol. Rev. 1983, 48, 147-160. [CrossRef]

(C) 2020 by the authors. Licensee MDPI, Basel, Switzerland. This article is an open access article distributed under the terms and conditions of the Creative Commons Attribution (CC BY) license (http://creativecommons.org/licenses/by/4.0/). 